\title{
Wolbachia infection frequencies in insects: evidence of a global equilibrium?
}

\author{
John H. Werren ${ }^{1 *}$ and Donald M. Windsor ${ }^{2}$ \\ ${ }^{1}$ Department of Biology, University of Rochester, Rochester, NY 14627, USA \\ ${ }^{2}$ Smithsonian Tropical Research Institute, Apartado 2072, Balboa-Ancon, Republic of Panama
}

\begin{abstract}
Wolbachia are a group of cytoplasmically inherited bacteria that cause reproduction alterations in arthropods, including parthenogenesis, reproductive incompatibility, feminization of genetic males and male killing. Previous general surveys of insects in Panama and Britain found Wolbachia to be common, occurring in 16-22\% of species. Here, using similar polymerase chain reaction methods, we report that $19.3 \%$ of a sample of temperate North American insects are infected with Wolbachia, a frequency strikingly similar to frequencies found in two other studies in widely separated locales. The results may indicate a widespread equilibrium of Wolbachia infection frequencies in insects whose maintenance remains to be explained. Alternatively, Wolbachia may be increasing in global insect communities. Within each of the three geographic regions surveyed, Hymenoptera are more frequently infected with A group Wolbachia and Lepidoptera more frequently infected with B group Wolbachia.
\end{abstract}

Keywords: Wolbachia; infection frequency; arthropods

\section{INTRODUCTION}

Wolbachia are a group of intracellular bacteria related to Rickettsia. These bacteria infect the reproductive tissues of arthropods, are transmitted through the egg cytoplasm and alter reproduction in their arthropod hosts in various ways (Werren 1997). Wolbachia are associated with cytoplasmic incompatibility (Breeuwer et al. 1992; O'Neill et al. 1992), parthenogenesis (Stouthamer et al. 1993), feminization of genetic males (Rousset et al. 1992) and male killing (Hurst et al. 1999). They have been implicated as a possible mechanism for rapid speciation in arthopods (Laven 1967; Breeuwer \& Werren 1990; Werren 1998; Shoemaker et al. 1999).

Sequencing of bacterial 16S rDNA and protein-coding genes has indicated at least four major subdivisions of Wolbachia. Two (designated A and B) are found in arthropods (Werren et al. 1995a; Zhou et al. 1998), including insects, crustacean isopods (Bouchon et al. 1998) and mites (Johanowicz \& Hoy 1995; Breeuwer 1997), and the other two (designated $\mathrm{C}$ and D) are found in nematodes (Bandi et al. 1998). A fifth subgroup (designated E) has recently been proposed based on a $16 \mathrm{~S}$ rDNA sequence for a Wolbachia found in a collembolan, a primitive insect (Vandekerckhove et al. 1999). The phylogenetic data also show extensive horizontal transmission of Wolbachia between insect taxa although the mechanisms are still unclear (Werren et al. 1995b).

Wolbachia are widespread and common in insects. In the first published systematic survey of Wolbachia distributions, Werren et al. (1995b) found over 16\% of a sample of insect species from Panama were infected with Wolbachia. Wolbachia were found in all the major orders of insects tested. Extrapolating to the global insect fauna, it was estimated that one to five million insect species are infected with these bacteria (Werren et al. 1995b). In a study using similar methods, West et al. (1998) found 22\% of British insects were infected. The latter study concen-

*Author for correspondence (werr@mail.rochester.edu). trated primarily on Lepidoptera (butterflies and moths) and Hymenoptera (wasps, bees and ants). However, systematic surveys of additional localities around the world have yet to be performed.

The objectives of this study were to (i) determine the distribution and type of Wolbachia in a sample of Neotemperate North American arthropods, and (ii) compare the results of this survey to two previous studies of lower Central America (Panama) and northern Europe (Britain). The results show a surprising consistency in the overall frequency of Wolbachia in these different geographic regions, as well as similar differences in the frequency of Wolbachia types between insect orders collected in the different regions.

\section{METHODS}

Arthropods (primarily insects) were collected and tested for the presence of Wolbachia using an assay based upon polymerase chain reaction (PCR) amplification of the $f t s z$ protein-coding gene and 16S rDNA from Wolbachia using methods similar to our previous surveys (Werren et al. 1995b; West et al. 1998). Details of the methods are described below.

\section{(a) Arthropod collection and handling}

Arthropods were collected from a single, wooded habitat $10 \mathrm{~km}$ south-east of Bloomington, IN $\left(39^{\circ} 10^{\prime} \mathrm{N}, 86^{\circ} 29^{\prime} \mathrm{W}\right)$ during August 1994, July 1997, August 1998 and November 1998. Entire animals or dissected ovaries were fixed in $95 \%$ ethanol. The fixed specimens were kept under refrigeration (around $4{ }^{\circ} \mathrm{C}$ ) until shipment to Rochester, NY, for further analysis, where they were kept under refrigeration until DNA extraction. Arthropod remains are stored in the insect voucher collection at the Smithsonian Tropical Research Institute, Panama City, Republic of Panama.

\section{(b) Template preparation}

DNA was extracted from the fixed individuals using either (i) eggs or ovaries, (ii) whole abdomens, or (iii) whole individuals (for small arthropods). The tissues were dissected in 
sterile, double-distilled, deionized water on a sterile Petri dish and then serially rinsed in droplets of sterile $\mathrm{H}_{2} \mathrm{O}$, prior to extraction of DNA using previously published methods (Werren et al. 1995b) or Qiaamp tissue extraction protocols (Smith \& Kelley 1994). Control DNA samples were prepared using pupae or adults of known infected and uninfected strains of Nasonia vitripennis.

\section{(c) Assay for Wolbachia}

A PCR was performed using Wolbachia-specific primers for the fts $Z$ bacterial cell-cycle gene to test for the presence of Wolbachia (Werren et al. 1995a,b). Arthropods yielding a product of the expected size were tentatively scored as positive for Wolbachia. Samples positive for Wolbachia based on this assay were then retested using primers specific for the A and B subdivisions of Wolbachia (ftsz, 16S or both; see $\S 2(\mathrm{~d})$ ). In addition, some products were sequenced and compared to known A and B group Wolbachia.

The absence of amplification using the general $f t s \mathcal{Z}$ primers (a presumptive negative) could be due either to (i) the absence of Wolbachia in the insect, (ii) failure of the DNA extraction procedure, or (iii) an incorrect concentration of DNA solution. As a control for the amplifiablility of the DNA extraction, samples that were negative for $f t s z$ were tested by using primers for highly conserved regions of eukaryotic $28 \mathrm{~S}$ rDNA (as described previously in Werren et al. (1995b)). From experience, we have often found positive amplifications following dilution of DNA. This is due to either an excess template DNA concentration or the presence of inhibiting substances. Therefore, the samples were tested at various dilutions ranging from 1:10 to 1:100 (depending upon the DNA concentrations apparent from ethydium bromide staining intensity). The maximum concentration yielding a $28 \mathrm{~S}$ rDNA positive result was then used to retest for Wolbachia with the general fts $Z$ primers. Samples that failed to yield a positive result by the $28 \mathrm{~S}$ rDNA primers for all concentrations (false negatives) were not included in the study. Additional positive controls using known infected insects (N.vitripennis) were performed with each set of PCR reactions. To confirm that the products amplified using the general fts $Z$ primers were from Wolbachia, the products were hybridized to radioactively labelled Wolbachia fts $Z$ as described previously (Werren et al. 1995b).

\section{(d) Screening using $16 S \mathrm{rDNA}$ primers}

We conducted a study to compare the efficiency of Wolbachia detection with the fts $z$ primers relative to the $16 \mathrm{~S}$ rDNA primers. Two sets of $16 \mathrm{~S}$ rDNA primers were used, which were designated W-Spec (Wolbachia specific) and W-E (Wolbachia Erlichia). The W-Spec primers were designed from the $3^{\prime}$ half of the $16 \mathrm{~S}$ rDNA gene in order to amplify a $438 \mathrm{bp}$ fragment. This region was chosen because it contains restriction sites which differ between A and B group Wolbachia, providing second confirmation of bacterial group (Werren et al. 1995a).

The W-E primers were designed to detect more divergent bacteria related to Wolbachia which may not be detected by the more specific sets. We do know that the general fts $z$ primers and 16S primers specific for Wolbachia amplify a diverse range of A and B Wolbachia and also successfully amplify the somewhat more divergent $\mathrm{C}$ and $\mathrm{D}$ group Wolbachia found in nematodes (Bandi et al. 1998). However, more divergent bacteria could be present in insects. To screen for such bacteria, primers from the 16S gene were designed, which amplify the product from both Wolbachia and related Rickettsia, including some Ehrlichia,
Cowdria and Anaplasma (Weisburg et al. 1991). A subset of samples were rescreened using these primers (designated W-E for Wolbachia Ehrlichia) in order to determine whether more divergent related bacteria were being missed in the samples.

\section{(e) PCR methods}

Amplification of the nearly complete Wolbachia fts $z$ sequence (1043-1055bp depending upon the Wolbachia strain) was accomplished with primers fts $\mathrm{ffl}$ and $f$ ts $\mathrm{rl}$ following previously published methods (Werren et al. 1995b; West et al. 1998). After the PCR, $8 \mu \mathrm{l}$ of amplified reaction product was run on a $1 \%$ agarose gel in order to determine the presence and size of the amplified DNA. Controls for the PCR amplifiability of the DNA solutions were conducted using the general eukaryotic $28 \mathrm{~S}$ rDNA primers $28 \mathrm{Sf}$ and $28 \mathrm{~S}$. In order to determine the Wolbachia group, primers for specific amplification of $\mathrm{A}$ and $\mathrm{B}$ group fts $Z$ were used. To confirm A and B status or to resolve ambiguities, A-specific $16 \mathrm{~S}$ and $\mathrm{B}$-specific $16 \mathrm{~S}$ primers were also used in some cases. The methods and primer sequences were as described previously (Werren et al. 1995a; West et al. 1998).

The 16S W-Spec primers used were W-Specf (CATACA TATTCGAAGGGATAG) and W-Specr (AGCTTCGAGTGAA ACGAATTC). These amplify a $438 \mathrm{bp}$ fragment and A and B Wolbachia can be distinguished by an RsaI restriction site present in B Wolbachia, which results in 146 and $292 \mathrm{bp}$ digestion. The conditions for the $\mathrm{W}$-Spec amplification were a 2 min period of $95^{\circ} \mathrm{C}$ pre-dwell, two cycles of $2 \mathrm{~min}$ at $95^{\circ} \mathrm{C}, 1 \mathrm{~min}$ at $60^{\circ} \mathrm{C}$ and $1 \mathrm{~min}$ at $72^{\circ} \mathrm{C}$, followed by 35 cycles of $30 \mathrm{~s}$ at $95^{\circ} \mathrm{C}, 1 \mathrm{~min}$ at $60^{\circ} \mathrm{C}$ and $45 \mathrm{~s}$ at $72{ }^{\circ} \mathrm{C}$ and a post-dwell period of $5 \mathrm{~min}$ at $72^{\circ} \mathrm{C}$.

The primers used for the amplification of Wolbachia, Ehrlichia and intermediate bacteria (W-E primers) were W-Ef (CAGACGgGTGAGTAATG $(\mathrm{C} / \mathrm{T})$ ATAG) and W-Er (TATCA CTGGGAGTTTCGTTAAAG). These amplify a fragment size of $1025 \mathrm{bp}$. As mentioned, these are designed from the moderately variable regions of $16 \mathrm{~S}$ rDNA and are relatively conserved among Wolbachia and related bacteria (some Ehrlichia, Anaplasma and Cowdria). The primers amplify the products from Wolbachia and Erhlichia canis, but not from Escherichia coli. Note that better primer design may now be possible with new sequence information on Erhlichia and relatives. The W-E PCR cycling conditions were two cycles of $2 \mathrm{~min}$ at $95^{\circ} \mathrm{C}, 1 \mathrm{~min}$ at $64^{\circ} \mathrm{C}$ and $2 \mathrm{~min}$ at $72^{\circ} \mathrm{C}$, followed by 35 cycles of $30 \mathrm{~s}$ at $95^{\circ} \mathrm{C}, 1 \mathrm{~min}$ at $64^{\circ} \mathrm{C}$ and $1 \mathrm{~min}$ at $72^{\circ} \mathrm{C}$ and a post-dwell period of $5 \mathrm{~min}$ at $72^{\circ} \mathrm{C}$.

\section{RESULTS}

\section{(a) Patterns in the Indiana sample}

A total of 145 insect species were screened for Wolbachia from 13 different orders, of which 19.3\% were positive for the bacteria (tables 1 and 2). As in the two previous surveys, Wolbachia were found in species of each of the major orders, including Diptera, Coleoptera and Lepidoptera, Hymenoptera and Orthoptera.

Of the 28 insects species positive for Wolbachia, 67.9\% were singly infected with A Wolbachia, 25.0\% were singly infected with B Wolbachia and 7.1\% were doubly infected with A and B Wolbachia (tables 3 and 4). The overall infection level with A bacteria (A and A plus B over the total species tested) was $14.5 \%$ and for B bacteria it was $6.2 \%$. Based on these frequencies, the overall infection frequency with both bacterial types $(1.4 \%)$ did not differ significantly from the random expectation if infection with one type were independent of infection with the 
Table 1. Distribution of Wolbachia

(The identifications of the arthropods tested are shown along with the results of the PCR assays. The presence of A, B or double (A plus B) infections was determined based upon the PGR assays (see §2). Arthropods that were not identified to species (or family) are placed in the appropriate family (or order). If multiple individuals were tested for a species, the number tested is indicated in parentheses. unid. sp., unidentified species; unid. family, unidentified family.)

\begin{tabular}{|c|c|c|c|}
\hline taxon & Wolbachia & taxon & Wolbachia \\
\hline \multicolumn{4}{|c|}{ Bombylidae } \\
\hline Coleoptera & & unid. sp. & - \\
\hline Cantharidae & & Caliphoridae & \\
\hline Chauligognathus pennsylvanicus sp. & - & unid. sp. & - \\
\hline Carabidae & & Chirnomidae & \\
\hline Harpalus pennsylvanicus & - & unid. sp. & - \\
\hline Agrasp. & - & Lonchaeidae & \\
\hline Galeritasp. & - & unid. sp. & - \\
\hline Cerambycidae & & Micropezidae & \\
\hline Tetraopestetraopthalmus & - & unid. sp. & A \\
\hline Typocerusvelutinus & - & Syrphidae & \\
\hline unid.sp. & - & Milesia virginiensis & - \\
\hline Cicindellidae & & Tabanidae & \\
\hline Cicindela sexguttata & $-(3)$ & unid. sp. & - \\
\hline Chrysomelidae & & Tachinidae & \\
\hline Chelymorpha cassidea & - & unid. sp. & - \\
\hline Diabrotica undecimpunctata & - & Tephritidae & \\
\hline Lema sexpunctata & - & unid. sp. & A \\
\hline Charidotella purpurata & A & Tipulidae & \\
\hline Charidotella sexpunctata & - & Tipula sp. nr. borealis & — \\
\hline Deloyala guttata & - & Tipula ultima & - \\
\hline Ciidae & & Ephemeroptera & \\
\hline Cis sp. 1 & - & Ephemeridae & \\
\hline Cis sp. 2 & - & Hexagenia sp. & - \\
\hline Coccinelidae & & Hemiptera & \\
\hline unid. sp. & $\mathrm{A}$ & Coreidae & \\
\hline Cycloneda munda & - & Leptoglossusclypealis & - \\
\hline Coleomegilla maculata & - & Gerridae & \\
\hline Curculionidae & & Gerris sp. 1 & - \\
\hline Cyrtepistomuscastaneus & A & Gerris sp. 2 & $\mathrm{~B}$ \\
\hline unid.sp. 1 & - & Lygaeidae & \\
\hline unid.sp. 2 & - & Oncopeltus fasciata & - \\
\hline unid. sp. 3 & - & Miridae & \\
\hline Dermestidae & & Lygus sp. 1 & - \\
\hline Dermesteslardarius & - & Lygus sp. 2 & - \\
\hline Elateridae & & Pentatomidae & \\
\hline unid.sp. & - & Euschistusvariolarius & - \\
\hline Erotylidae & & Murgantia histrionica & - \\
\hline Megalodacnesp. & - & Rhopalidae & \\
\hline Lycidae & & Leptocoris trivittatus & - \\
\hline Calypteron terminale & - & Reduviidae & \\
\hline Calypteron reticulatum & - & Arilus cristatus & - \\
\hline Meloidae & & Homoptera & \\
\hline Epicauta cinerea & B & Aphidae & \\
\hline Nitidulidae & & unid.sp. & - \\
\hline Lobiopa sp. & - & Cicadellidae & \\
\hline Carpophilus sp. & - & unid. sp. & - \\
\hline Scarabeidae & & Membracidae & \\
\hline Phyllophagasp. & - & unid. sp. & - \\
\hline Staphylinidae & & Hymenoptera & \\
\hline unid. sp. 1 & - & Andrenidae & \\
\hline unid.sp. 2 & A & Panurginae (unid.sp.) & $\mathrm{A}$ \\
\hline Tenebrionidae & & Apidae & \\
\hline Bolitotherus cornutus & - & Ceratinasp. & A \\
\hline Diptera & & Bombus sp. & - \\
\hline Asilidae & & Apis mellifera & - \\
\hline unid.sp. 1 & - & Halictinae sp. & $\mathrm{A}$ \\
\hline unid. sp. 2 & - & Melissodes rustica & - \\
\hline
\end{tabular}


Table 1. (Cont.)

\section{taxon}

unid. sp.

unid. sp.

Bethylidae unid. sp.

Chrysididae unid. sp.

Cynipidae unid. sp.

Eumenidae Eumenes fraternus Monobia quadirdens Zethus sp. unid. sp. unid. sp.

Formicidae Formica sp. 1

Formica sp. 2

Leptothorax sp. unid. sp.

Halictidae Augochlorapura Lasioglossum sp.

Ichneumonidae unid.sp. 1 unid.sp. 2 unid.sp. 3 unid. sp. 4 unid.sp. 5 unid.sp. 6 unid. sp. 7

Leucospidae Leucospis sp.

Mutilidae Mutilla occidentalis

Perilampidae Perilampus sp.

Pompilidae unid.sp. 1 unid.sp. 2 Auplopus sp.

Sphecidae Ammophila sp. Pemphredon sp. Chalybion sp. unid.sp. 1 unid.sp. 2

Tenthredinidae unid. sp.

Torymidae unid. sp.

Vespidae

Dolichovespula maculata Dolichovespulanorvegicensis Polistesfuscatus

Isoptera

Rhinotermitidae Reticulotermesflavipes

Lepidoptera

Arctiidae Apantesis virgo
Spilosoma virginica

\section{Wolbachia}

A

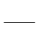

A

B

B

-

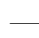

AB

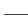

A

$-$

A

A

A
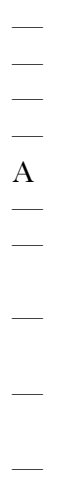

A

$-$
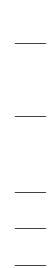

$-$

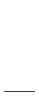

$-$ taxon

Wolbachia

Ctenuchidae

Cisseps fulvicollis unid.sp.

Danaiidae Danausplexippus

Geometridae Anacamptoides sp.

Eubaphemendica $-(2)$

unid. sp. 1

unid.sp. 2

Hesperiidae Epargyreus clarus

Lycaenidae Plebejus sp.

Noctuidae

Pyrrhiasp. unid. sp. 1 unid.sp. 2

Nymphalidae Speyeriacybele Papilioglaucus Phycoides tharos unid.sp.

Pieridae Colias sp.

Pterophoridae unid. sp.

Satyridae Enodia portlandia

Mecoptera

Panorpidae Panorpabichae

Odonata

Calopterygidae Calopteryx maculata

Orthoptera

Acrididae Melanoplus sp.

Blattidae Percoblattasp.

Gryllidae Phylopalpus sp.

A

Orcharis sp.

unid.sp.

unid.sp.

Mantidae

Tenodera sinensis

Phasmidae

Diaphermomerafemorata

Tettigonidae

Scudderiafurcata

Conocephalus nemoralis

Amblycorpryphasp.

Psocoptera

Psocidae unid.sp.

Siphnoptera

Pulicidae

Ctenocephalides canis

Thysanura

Machilidae Machilis sp. 
Table 1. (Cont.) taxon

Arachnida

Araneae

Araneidae

Micrathena gracillis

Araneussp.

Achaeranea tipidariorum

Lycosidae

Lycosa sp.

Salticidae unid. sp.

Theridiidae

Achaeraneasp.

Tidarren sp.

Thomisidae Misumena sp.

Pholcidae

Pholcus phalangiodes

Ixodidae

Dermacentorvariabilis

Opiliones

Phalangidae

Leiobunum (?) sp.

Opiliones sp.

Chilipoda

Lithobiidae

Lithobius sp.

unid. family

Diplopoda

unid. family

Crustacea

Isopoda

unid. family

unid. family

Amphipoda

unid. family
Wolbachia

$-$

$-$
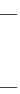

A

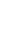

$-$

$-$

$-$

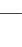

other $(0.9 \%)$ (Pearson $\chi^{2}=1.50, p=0.22$ and d.f. $=1$ ). The pattern of A and B infections in the Indiana sample contrasted with studies in other locations (see below).

Ten arachnid species were tested in the temperate North American sample and one crab spider (Misumena sp.) was found to be weakly positive with A Wolbachia. This is the first spider that has so far tested positive for Wolbachia (zero out of ten from tropical North America). However, follow-up sampling of this species has not yet been performed. Although Wolbachia are found in mites (Breeuwer 1997), further work is needed to clarify whether spiders harbour Wolbachia.

\section{(b) Comparing geographic regions}

Comparisons between the three surveys are shown in tables 2-4. The surveys were for lower Central America (Panama), temperate Europe (Britain) and temperate North America (Indiana). Some surveys of other insects have recently been published (Bouchon et al. 1998; Hariri et al. 1998; Wenseleers et al. 1998). However, these were focused upon groups where there was some prior knowledge of Wolbachia infections and, therefore, the infection frequencies are likely to be biased upwards. In the three surveys compared here, the genera and species were selected arbitrarily with respect to any prior knowledge of infection status. In addition, similar methods were used in all three locales, making the results more comparable.

All three sites showed remarkable consistency in their overall frequencies of Wolbachia infections: $17 \%$ for Panama, 22\% for Britain and 19\% for Indiana. This consistency is surprising because of the stochasticity of the samples. The relative representations of the different orders differed between sites (e.g. 24, 36 and $0 \%$ for Coleoptera from Indiana, Panama and Britain, respectively). The European samples were particularly focused. The samples were taken from a community of leafmining Lepidoptera and associated parasitoids and from an arbitrary sampling of Lepidoptera arriving at bait traps. Nevertheless, the consistent infection frequencies imply that some general factors may result in a largescale equilibrium in infection frequency.

Although all three locales showed similar overall frequencies, there were interesting contrasts (table 3). First, among infections, the Indiana samples were significantly more likely to harbour group A than group B bacteria $(70 \% \mathrm{~A}, n=30)$ (Pearson $\chi^{2}=5.35, p=0.021$ and d.f. $=1)$, whereas Panama $(49 \% \mathrm{~A}, n=35)$ and Britain (42\% A, $n=19)$ showed similar infection levels with group A and B bacteria.

The frequency of double infections (A and B) detected among infected species also differed significantly between sites (table 3), with 34.6\% in Neotropical North America, $5.6 \%$ in northern Europe and $7.1 \%$ in Neotemperate North America (Pearson $\chi^{2}=6.2, p=0.045$ and d.f. $=2$ ). In particular, the two temperate regions showed similar levels of double infections. The frequency of double infections in Panama was greater than expected by chance if the probabilities of infection with $\mathrm{A}$ and $\mathrm{B}$ are independent (Werren et al. 1995b), whereas the double infection frequencies were not significantly higher in Britain (West et al. 1998) or Indiana (this study). Possible explanations for these differences are discussed later.

\section{(c) Comparing insect orders}

The sample sizes were sufficient for beginning to compare different orders of insects betwen regions. Although the frequency of infected Hymenoptera was lower in the British sample $(13 \%)$ than in the Panama and Indiana samples (26 and $31 \%$, respectively), the differences between all three sites were not quite significant (Pearson $\chi^{2}=5.48, p=0.064$ and d.f. $=2$ ). Similarly, the infection frequencies differed between locales among the Lepidoptera, but not significantly so based on the current sample sizes (Pearson $\chi^{2}=4.97, p=0.083$ and d.f. $=2)$. The sample sizes in other orders were not large enough to permit additional comparisons.

Interesting differences occurred between the insect orders in their relative frequencies of $\mathrm{A}$ and $\mathrm{B}$ infections (table 4). The Hymenoptera had a higher incidence of infection with A Wolbachia than with B Wolbachia in each location. In contrast, the Lepidoptera were more likely to be infected with B Wolbachia. Summing across locations, the Hymenoptera were significantly more likely to be infected with A Wolbachia (21.2\%) than with B Wolbachia $(3.5 \%) \quad\left(\right.$ Pearson $\chi^{2}=12.43, p<0.001$ and d.f. $=1$ ), whereas the Lepidoptera were significantly less likely to be infected with A Wolbachia (6.1\%) than with B Wolbachia $(20.4 \%)$ (Pearson $\chi^{2}=6.477, p=0.011$ and 
Table 2. Comparison of the numbers of species of Neotemperate, Neotropical and Palaeotemperate insects and arachnids testing positive for Wolbachia

\begin{tabular}{|c|c|c|c|c|c|c|c|c|c|}
\hline \multirow[b]{3}{*}{ group } & \multicolumn{3}{|c|}{ Indiana } & \multicolumn{3}{|c|}{ Panama } & \multicolumn{3}{|c|}{ Britain } \\
\hline & \multicolumn{2}{|c|}{ infected } & \multirow{2}{*}{$\begin{array}{l}\text { number } \\
\text { tested }\end{array}$} & \multicolumn{2}{|c|}{ infected } & \multirow{2}{*}{$\begin{array}{c}\text { number } \\
\text { tested }\end{array}$} & \multicolumn{2}{|c|}{ infected } & \multirow{2}{*}{$\begin{array}{r}\text { numbe } \\
\text { tested }\end{array}$} \\
\hline & $n$ & $\%$ & & $n$ & $\%$ & & $n$ & $\%$ & \\
\hline Insecta & 28 & 19.3 & 145 & 26 & 16.9 & 154 & 18 & 21.7 & 83 \\
\hline Coleoptera & 5 & 14.3 & 35 & 6 & 10.5 & 57 & - & - & - \\
\hline Hymenoptera & 14 & 31.1 & 45 & 6 & 26.1 & 23 & 6 & 13.3 & 45 \\
\hline Lepidoptera & 3 & 14.3 & 21 & 7 & 16.3 & 43 & 12 & 35.3 & 34 \\
\hline other orders & 6 & 13.6 & 44 & 7 & 22.6 & 31 & 0 & 0.0 & 4 \\
\hline Arachnida & 1 & 8.3 & 12 & 0 & 0.0 & 3 & - & - & - \\
\hline all arthropods & 29 & 18.5 & 157 & 26 & 16.6 & 157 & 18 & 21.7 & 83 \\
\hline
\end{tabular}

Table 3. Comparison of the numbers of singly and doubly infected species by region

\begin{tabular}{|c|c|c|c|c|c|c|}
\hline region & A & $\mathrm{B}$ & $\mathrm{AB}$ & percentage $\mathrm{AB}$ & total & total percentage infected \\
\hline Indiana & 19 & 7 & 2 & 7.1 & 145 & 19.3 \\
\hline Panama & 8 & 9 & 9 & 34.6 & 154 & 16.9 \\
\hline Britain & 7 & 10 & 1 & 5.6 & 83 & 21.7 \\
\hline
\end{tabular}

Table 4. Comparison of the numbers of singly and doubly infected species in two insect orders by region

\begin{tabular}{|c|c|c|c|c|c|c|}
\hline region & $\mathrm{A}$ & $\mathrm{B}$ & $\mathrm{AB}$ & percentage $\mathrm{AB}$ & total & total percentage infected \\
\hline \multicolumn{7}{|c|}{ Hymenoptera } \\
\hline Indiana & 11 & 2 & 1 & 7.1 & 45 & 31.1 \\
\hline Panama & 6 & 0 & 0 & 0.0 & 23 & 26.1 \\
\hline Britain & 5 & 0 & 1 & 16.7 & 45 & 13.3 \\
\hline total & 22 & 2 & 2 & 7.7 & 113 & 23.0 \\
\hline \multicolumn{7}{|c|}{ Lepidoptera } \\
\hline Indiana & 0 & 2 & 1 & 33.3 & 21 & 14.3 \\
\hline Panama & 0 & 4 & 3 & 42.9 & 43 & 16.3 \\
\hline Britain & 2 & 10 & 0 & 0.0 & 34 & 35.3 \\
\hline total & 2 & 16 & 4 & 18.2 & 98 & 22.4 \\
\hline \multicolumn{7}{|c|}{ other insect orders } \\
\hline Indiana & 8 & 3 & 0 & 0.0 & 79 & 13.9 \\
\hline Panama & 2 & 5 & 6 & 46.2 & 88 & 14.8 \\
\hline Britain & 0 & 0 & 0 & 0.0 & 4 & 0.0 \\
\hline total & 10 & 8 & 6 & 0.0 & 171 & 14.0 \\
\hline
\end{tabular}

d.f. $=1)$. The Hymenoptera and Lepidoptera differed significantly in their relative infection frequencies with A and B Wolbachia (Fisher's exact test $p<0.001$ and $n=54$ ).

\section{(d) Comparisons of assay methods}

Of the initial 89 samples that were screened for Wolbachia using the general fts $Z$ primers (and which were positive for $28 \mathrm{~S}$ rDNA amplification), ten (11.2\%) were positive for Wolbachia. We rescreened these samples using W-E primers. A total of six additional insects tested positive for the W-E primers. Initially, it was believed that these may represent divergent types of Wolbachia or related species, because the $\mathrm{W}$-E primers are more generally designed to amplify bacteria with sequences in the range of Wolbachia to Ehrlichia, the most closely related other genera of Rickettsia (Breeuwer et al. 1992; O'Neill et al. 1992). However, partial sequencing of the $16 \mathrm{~S}$ product revealed these to be typical A group Wolbachia (data not shown). Subsequent amplification with A-specific $f$ ts $Z$ and $16 \mathrm{~S}$ primers confirmed this result. Therefore, no Ehrlichia or divergent Wolbachia were detetected in the sample, although the initial screen with the $f t s z$ general primers did miss bacteria detected with the W-E primers. Subsequently, the complete sample set (151) was screened with either the W-E, W-Spec or both sets of primers in addition to an initial screen with the fts $Z$ general primers. Seventeen infections were detected with fts $z$ and an additional 11 were detected by the W-E or W-Spec 
primers. All samples detected by the W-E primers also tested positive for the $\mathrm{W}$-Spec primers (and vice versa). Most of the 11 samples that tested negative in the initial fts $Z$ screen were positive for the A- or B-specific fts $Z$ primers.

The results indicate that, in this particular sample, the $16 \mathrm{~S}$ rDNA primers were more sensitive in detecting Wolbachia infections $(18.5 \%)$ than the general fts $Z$ primers $(11.3 \%)$. We attributed this to the relative storage ages of the samples when they were tested. We conducted a study showing that the detection of Wolbachia by fts $Z$ declines with the time of the samples in storage $(95 \%$ ethanol and refrigeration at $4{ }^{\circ} \mathrm{C}$ or $-20^{\circ} \mathrm{C}$ ), whereas the detection levels with the $\mathrm{W}$-E and $\mathrm{W}$-Spec primers remained high (C. Kennedy and J. H. Werren, unpublished data). This is most probably due to some degradation of the DNA within the samples, which affects the amplification of the fts $Z$ product more adversely. It should be noted that the British survey found nearly identical infection rates using the $f t s Z$ and $\mathrm{W}$-E primers on freshly collected material and the Panama sample was also tested shortly after collection. Therefore, we concluded that using the overall detection level in the Indiana samples was most appropriate for comparisons to the British and Panama surveys.

\section{(e) Large-scale Wolbachia dynamics}

The overall frequencies of Wolbachia were similar (ca. $20 \%$ ) in the samples of insects from the three different geographic regions, i.e. tropical North America, temperate Europe and temperate North America. This result provides a first possible glimpse of the global dynamics of Wolbachia.

What might be determining the frequency of Wolbachia infections on a large scale? In simple terms, the dynamics of infected species will be a balance between the rates of acquisition of infections by species and the rates of loss of infected species. Assuming for the moment that there are no differences in the speciation or extinction rates of infected and uninfected species, then the frequency of infected species $(f)$ at equilibrium may be approximated by $f(1-f) T=f L$, where $T$ is the transmission rate to new species and $L$ is the loss rate of infections in infected species. Normalizing $L=k T$, the equilibrium frequency is $f^{*}=1-k$. Under these conditions, the loss rate is then expected to be $c a$. $80 \%$ of the new infection rate at equilibrium to account for frequencies of $c a .20 \%$ in the three regions.

\section{DISCUSSION}

The results indicated similar levels of Wolbachia infection among insect species from three different locales spanning two continents. However, the statuses of most of the species in these samples were based on a single or few individuals. As a result, species with infections not at fixation were less likely to test positive and the actual frequencies of the infected species were almost certainly higher than those shown in these studies. Nevertheless, testing of one or a few individuals per species is probably the best initial approach to obtaining an estimation of the overall patterns of infected species. A subset of species should be sampled more extensively in order to determine the frequency distribution of infection polymorphisms. Once this is accomplished, broader scale surveys can be adjusted to estimate the numbers of infected species more accurately.

A second problem with these data concerns the unsystematic sampling scheme. In Panama, insects for which there was a reasonable chance of obtaining identification at least to genus level were collected. Due to the expertise available (and the proclivities of the collectors), the sampling focused more on Coleoptera, Hymenoptera and Lepidoptera. In the British samples, similar principles applied with sampling primarily of Lepidoptera and Hymenoptera. Some of these species were also from a related community of leaf-mining Lepidoptera and associated parasitoids. In the current sample from Indiana, attempts were made to sample a wider spectrum of insect orders. However, most samples came from the common orders mentioned previously. All the sampling efforts were likely to have been biased towards locally abundant species. However, it should be pointed out that the species were selected without prior knowledge of infections in them or closely related species and, therefore, the sample was not biased by such an effect.

Several taxon-focused surveys of insects have recently been performed in mushroom-feeding Drosophila (Werren \& Jaenike 1995), other Drosophila (Bourtzis et al. 1996), stalk-eyed flies (Hariri et al. 1998), parthenogenetic gall wasps (Schilthuizen \& Stouthamer 1998) and ants (Wensleers et al. 1998). Several of these have shown frequencies of infection dramatically higher than found in the broader surveys reported here. It should be kept in mind that there was detection bias in several of these surveys that was not present in the ones we conducted. For example, the survey on gall wasps arose from the high frequency of parthenogenesis in these insects, a reproductive mode known to be induced by Wolbachia in some Hymenoptera (Stouthamer et al. 1993), and the interest in ants resulted partly from earlier detection of Wolbachia in these insects (Werren et al. 1995b). Thus, groups with a higher frequency of Wolbachia infections may be preferentially surveyed due to preliminary results indicating infection incidences.

Such findings suggest that certain taxonomic groups may be more prone to acquiring or maintaining Wolbachia infections than others. For example, over $50 \%$ of a set of south-east Asian ant species tested positive for Wolbachia (Wensleers et al. 1998). This could indicate that ants are particularly prone to acquiring the bacteria, although it has not yet been established whether this is a feature of ants in general or of ants (or insects) from the region surveyed. In addition, there are clear differences between insect orders in their relative frequencies of infection with A versus B Wolbachia. In particular, Hymenoptera show higher infection levels with A Wolbachia and Lepidoptera show higher infection levels with B Wolbachia. These results may indicate differences in the ability of $\mathrm{A}$ and $\mathrm{B}$ Wolbachia to infect different taxa, differences in the retention of such infections or historical differences in the emergence and spread of Wolbachia within these taxa. The frequency of double (A plus B) infections was found to be higher in the Neotropical sample (Panama) than in either temperate sample (Britain or Indiana). Additional study is needed in order to determine whether this pattern 
holds true. If correct, then it implies different horizontal infection dynamics in these different regions.

A major question is whether Wolbachia are in some form of global equilibrium where the numbers of newly infected species approximately equal the numbers lost. Alternatively, these bacteria may be undergoing an expansion, in which case the infection frequencies are not at equilibrium. In particular, it has been argued that Wolbachia may be undergoing expansions into new host species as a result of human ecological disturbances (Werren 1997). Whether Wolbachia are at global equilibrium or undergoing expansion depends upon the rates of gain and loss of infected species.

It is clear that Wolbachia are horizontally transmitted between host species, although the mechanisms of the transmission are still uncertain. Werren et al. (1995b) found phylogenetic evidence of intertaxon transmission between parasitic wasps (Nasonia) and their blowfly hosts (Protocalliphora) and Vavre et al. (1999) found similar evidence for some drosophilid parasitoids. In further support of parasitoid-host insect transmission, Heath et al. (1999) found that Wolbachia can be naturally transmitted from infected Drosophila simulans to its larval parasitoid Leptopilina boulardi in the laboratory, although the bacteria had seriously reduced transmission in the novel host. However, West et al. (1998) and Schilthuizen \& Stouthamer (1998) did not find phylogenetic evidence of horizontal transmission between parasitoids and hosts in two different insect guilds. The general view is that ecologically intimate species (e.g. parasites and hosts) are conduits for the transmission of these intracellular bacteria, although the data sets are not yet extensive enough to determine at what rates parasitoid-host versus other mechanisms of transfer occur.

Once established in a species, cytoplasmic-incompatibilityinducing Wolbachia can rapidly increase in host populations (Turelli \& Hoffmann 1991; Turelli 1994). Similarly, parthenogenesis-inducing and feminizing Wolbachia have selective advantages in host populations due to increased production of the (vertically) transmitting sex, i.e. females. The mechanisms of loss of Wolbachia from infected species are much less clear. It has been posited that, once cytoplasmic-incompatibility-inducing Wolbachia become common in a population, mutation accumulation will result in a slow decline in the bacteria able to cause cytoplasmic incompatibility (Hurst \& McVean 1996). However, this is just one possible evolutionary trajectory for the infection (Frank 1997). Others include host genetic changes that suppress modification in the male (Turelli 1994), which could also lead to eventual loss, invasion by a second infection (which can lead to double-infected species) and evolution of new incompatibility types within a species, which can maintain the infection (Werren 1998).

It is currently unknown how frequent loss occurs relative to the infection of new species. However, it is clear that, to achieve global equilibrium in the frequency of infected species, some sort of equilibrium between these processes is necessary. As indicated by the model above, if there is global equilibrium then the rates of loss must be ca. $80 \%$ the new infection rate to account for the observed infection frequency of $c a .20 \%$. Therefore, we might expect to find many species where Wolbachia are at intermediate or low frequency and in which hosts have evolved resistance to Wolbachia, as has been suggested to occur in Drosophila melanogaster (Clancy \& Hoffmann 1996). In addition, if a common mechanism of Wolbachia loss is evolution of modification rescue-deficient Wolbachia $(\bmod -\operatorname{resc}+$ and $\bmod -\operatorname{resc}-)$ within a species, then we should expect to find many host species in which closely related strains of Wolbachia occur, which are $\bmod -\operatorname{resc}+, \bmod -\operatorname{res}-$ and $\bmod +\operatorname{resc}+$. So far, this has not been the case; where 'defective' and functional Wolbachia are found in the same species, they appear to be from different bacterial strains (Zhou et al. 1998). Finally, differential extinction and speciation rates of infected and uninfected species could be a factor influencing the frequency of Wolbachia in insect communities.

In conclusion, surveys in three locales on two continents showed similar levels of infection of Wolbachia (ca. 20\%) and higher levels of A Wolbachia infection in Hymenoptera and B Wolbachia infection in Lepidoptera. Double infections occurred more frequently in the Neotropical sample (Panama) than in either of the temperate samples (Indiana or Britain). Additional regional-, taxon- and community-based sampling of Wolbachia will provide the kinds of data sets needed to draw robust inferences concerning the distribution, evolution and dynamics of Wolbachia. In particular, further studies are needed to resolve whether Wolbachia are undergoing an expansion or are at global equilibrium.

Special thanks are due to G. Kennedy and R. Goodwin (University of Rochester) for assistance in the laboratory, G. Byers (Diptera), B. Alexander (Hymenoptera) and R. Brooks (Hymenoptera) at the Snow Museum (University of Kansas) for species identifications, and G. Keller and S. Bordenstein for comments. Funds for this project were provided by the National Science Foundation and Mellon Foundation to J.H.W. and by the Smithsonian Tropical Research Institute to D.W.

\section{REFERENCES}

Bandi, C., Anderson, T. J. C., Genchi, C. \& Blaxter, M. L. 1998 Phylogeny of Wolbachia in filarial nematodes. Proc. R. Soc. Lond. B 265, 2407-2413.

Bouchon, D., Rigaud, T. \& Juchault, P. 1998 Evidence for widespread Wolbachia infection in isopod crustaceans: molecular identification and host feminization. Proc. R. Soc. Lond. B 265 , 1081-1090.

Bourtzis, K., Nirgianaki, A., Markakis, G. \& Savakis, C. 1996 Wolbachia infection and cytoplasmic incompatibility in Drosophila species. Genetics 144, 1063-1073.

Breeuwer, J. A. J. 1997 Wolbachia and cytoplasmic incompatability in the spider mites Tetranychus urticae and T. turkestani. Heredity 79, 41-47.

Breeuwer, J. A. J. \& Werren, J. H. 1990 Microorganisms associated with chromosome destruction and reproductive isolation between two insect species. Nature 346, 558-560.

Breeuwer, J. A. J., Stouthamer, R., Burns, D. A., Pelletier, D. A., Weisburg, W. G. \& Werren, J. H. 1992 Phylogeny of cytoplasmic incompatibility microorganisms in the parasitoid wasp genus Nasonia (Hymenoptera: Pteromalidae) based on 16S ribosomal DNA sequences. Insect Mol. Biol. 1, 25-36.

Clancy, D. J. \& Hoffmann, A. A. 1996 Cytoplasmic incompatibility in Drosophila simulans: evolving complexity. Trends Ecol. Evol. 11, 145-146.

Frank, S. A. 1997 Cytoplasmic incompatibility and population structure. 7. Theor. Biol. 184, 327-330. 
Hariri, A. R., Werren, J. H. \& Wilkinson, G. S. 1998 Distribution and reproductive effects of Wolbachia in stalkeyed flies (Diptera; Diopsidae). Heredity 81, 254-260.

Heath, B. D., Butcher, R. D. J., Whitfield, W. G. \& Hubbard, S. F. 1999 Horizontal transfer of Wolbachia between phylogenetically distant insect species by a naturally occurring mechanism. Curr. Biol. 9, 313-316.

Hurst, L. D. \& McVean, G. T. 1996 Clade selection, reversible evolution, and the persistence of selfish elements: the evolutionary dynamics of cytoplasmic incompatibility. Proc. R. Soc. Lond. B 263, 97-104.

Hurst, G., Jiggins, F. M., Graf von der Schulenburg, J. H., Bertrand, D., Werren, J. H., West, S., Goriacheva, I. I., Zakharov, I. A., Stouthamer, R. \& Majerus, M. E. N. 1999 Male killing Wolbachia in two species of insects. Proc. R. Soc. Lond. B 266, 735-740.

Johanowicz, D. L. \& Hoy, M. A. 1995 Molecular evidence for A-Wolbachia endocytobiont in the predatory mite Metaseiulus occidentalis. 7. Cell. Biochem. 21A 198.

Laven, H. 1967 Speciation and evolution in Culex pipiens. In Genetics of insect vectors of diseases (ed. J. W. Wright \& R. Pai), pp. 251-275. Elsevier and North-Holland.

O’Neill, S. L., Giordano, R., Colbert, A. M. E., Karr, T. L. \& Robertson, H. M. 1992 16S rRNA phylogenetic analysis of the bacterial endosymbionts associated with cytoplasmic incompatibity in insects. Proc. Natl Acad. Sci. USA 89, 2699-2702.

Rousset, F., Bouchon, D., Pintureau, B., Juchault, P. \& Solignac, M. 1992 Wolbachia endosymbionts responsible for various alterations of sexuality in arthropods. Proc. R. Soc. Lond. B 250, 91-98.

Schilthuizen, M. \& Stouthamer, R. 1998 Distribution of Wolbachia among the guild associated with the parthenogenetic gall wasp Diplolepis rosae. Heredity 81, 270-274.

Shoemaker, D. D., Katju, V. \& Jaenike, J. J. 1999 Wolbachia and the evolution of reproductive isolation between Drosophilla recens and Drosophila subquinaria. Evolution 53, 1157-1164.

Smith, B. \& Kelley, M. R. 1994 Rapid genomic DNA purification from Drosophila melanogaster for restriction digest and PCR. 7. Natl Inst. Hlth Res. 6, 78.

Stouthamer, R., Breeuwer, J. A. J., Luck, R. F. \& Werren, J. H. 1993 Molecular identification of microorganisms associated with parthenogenesis. Nature 361, 66-68.

Turelli, M. 1994 Evolution of incompatibility-inducing microbes and their hosts. Evolution 45, 1500-1513.
Turelli, M. \& Hoffmann, A. A. 1991 Rapid spread of an inherited incompatibility factor in California Drosophila. Nature 353 , 440-442.

Vandekerckhove, T., Watteyne, S., Willems, A., Swing, J. G., Mertens, J. \& Gillis, M. 1999 Phylogenetic analysis of the 16S rDNA of the cytoplasmic bacterium Wolbachia from the novel host Folsomia candida (Hexapoda, Collembola) and its implications for wolbachial taxonomy. FEMS Microbiol. Lett. 180, 279-286.

Vavre, F., Fleury, F., Lepetit, D., Fouillet, P. \& Bouletreau, M. 1999 Phylogenetic evidence for horizontal transmission of Wolbachia in host-parasitoid associations. Mol. Biol. Evol. 16, 1711-1723.

Weisburg, W. G., Barns, S. M., Pelletier, D. A. \& Lane, D. J. 1991 16S ribosomal DNA amplication for phylogenetic study. 7. Bacteriol. 173, 697-703.

Wenseleers, T., Ito, F., Van Borm, S., Huybrechts, R., Volckaert, F. \& Billen, J. 1998 Widespread occurrence of the microorganism Wolbachia in ants. Proc. R. Soc. Lond. B 265, $1447-1452$.

Werren, J. H. 1997 Biology of Wolbachia. A. Rev. Entomol. 42, 587-609.

Werren, J. H. 1998 Wolbachia and speciation. In Endless forms: species and speciation (ed. D. Howard \& S. Berlocher), pp. 245260. Oxford University Press.

Werren, J. H. \& Jaenike, J. 1995 Wolbachia and cytoplasmic incompatibility in mycophagous Drosophila and their relatives. Heredity 75, 320-326.

Werren, J. H., Zhang, W. \& Guo, L. 1995a Evolution of Wolbachia: reproductive parasites of arthopods. Proc. R. Soc. Lond. B 251, 55-63.

Werren, J. H., Windsor, D. \& Guo, L. $1995 b$ Distribution of Wolbachia among Neotropical arthropods. Proc. R. Soc. Lond. B 262, 197-204.

West, S. A., Cook, J. M., Werren, J. H. \& Godfray, H. C. 1998 Wolbachia in two insect host-parasitoid communities. Mol. Ecol. 7, 1457-1465.

Zhou, W., Rousset, F. \& O’Neill, S. 1998 Phylogeny and PCRbased classification of Wolbachia strains using wsp gene sequences. Proc. R. Soc. Lond. B 265, 509-515.

As this paper exceeds the maximum length normally permitted, the authors have agreed to contribute to production costs. 